Musées, Patrimoine et Culture scientifiques et techniques

$153 \mid 2014$

mai-juin 2014

\title{
Le récolement dans les services d'archives
}

\section{Agnès Vatican}

URL: http://journals.openedition.org/ocim/1368

DOI: 10.4000/ocim.1368

ISSN: $2108-646 \mathrm{X}$

\section{Publisher}

OCIM

Printed version

Date of publication: 25 June 2014

ISSN: 0994-1908

\section{Electronic reference}

Agnès Vatican, «Le récolement dans les services d'archives », La Lettre de l'OCIM [Online], 153 | 2014, Online since 25 June 2016, connection on 19 April 2019. URL : http://journals.openedition.org/ ocim/1368; DOI : 10.4000/ocim.1368 


\section{Le récolement dans les services d'archives}

\section{Agnès Vatican}

Directrice des Archives départementales de la Gironde

Dans les services d'archives, le récolement est une pratique relativement ancienne, qui peut revêtir un caractère réglementaire ou être considéré comme un outil préalable au traitement d'un fonds.

Pour les archives départementales, c'est le règlement de 1921 qui le rend obligatoire. L'instruction du 9 janvier 1922 sur les archives communales et hospitalières, l'institue également. Cette obligation a été réaffirmée par le décret n88-849 du 28 juillet 1988 sur le contrôle scientifique et technique de l'État.

Rédigé sous la forme d'un procès-verbal, il doit être établi dans l'année de prise de fonction pour les archivistes départementaux et communaux. Il doit être également dressé en cas de déménagement (avant et après déménagement des fonds), ainsi qu'en cas de sinistre majeur. Le procès-verbal de récolement inclut alors la description des locaux d'archivage et de leur aménagement ainsi que l'état topographique des fonds.

Un cas particulier concerne les archives communales : l'article 4 de l'arrêté interministériel du 31 décembre 1926 portant règlement des archives communales modifié, toujours en vigueur, prescrit l'établissement d'un procès-verbal de décharge et de prise en charge des archives de la commune, auquel est annexé un récolement sommaire ou détaillé, à chaque changement de maire ou de municipalité. Cette obligation est donc rappelée à chaque élection municipale.

La circulaire AD97-4 du 1 $^{\text {er }}$ septembre 1997 de la Direction des Archives de France (aujourd'hui service interministériel des archives de France), a précisé les modalités de réalisation de ces récolements réglementaires (www.archivesdefrance.culture.gouv.fr/static/1774). Le récolement des fonds d'archives doit s'effectuer de façon topographique, par bâtiment, niveau, magasin, travée et tablette. Le relevé est toujours fait de gauche à droite et de bas en haut. Il constate la présence (et les lacunes) des documents au vu des cotes, et les répertorie par séquence continue de cotes. Son établissement nécessite dans la pratique un contrôle avec les instruments de recherche, notamment pour repérer les lacunes ou déclassements. Mais il doit aussi inclure des fonds non classés, dépourvus de cote, récolés alors « en vrac » ou avec une cotation provisoire.

Si sa fonction première est de constituer un procès-verbal de prise en charge des fonds, le récolement, dont la communication au public est interdite pour des raisons de sécurité des fonds, constitue également un instrument de recherche interne : il permet de connaître le volume des fonds conservés, calculé en mètres linéaires, et la localisation de chaque article (unité documentaire de cotation et de description).

Le développement de logiciels de gestion des archives permet désormais de disposer d'outils de récolement permanent, dont la mise à jour peut se faire au fil de l'eau. Pour plusieurs de ces logiciels métiers, le récolement sert aussi de socle aux modules de communication en salle de lecture et de prêt de documents (traitement interne, restauration, numérisation, prêt pour exposition par exemple). À ce titre, il inclut les mentions d'incommunicabilité pour les archives publiques (Code du Patrimoine) et celles de restrictions de consultation liées au mauvais état matériel des documents ou à l'existence de supports de substitution (microfilm ou fichier numérique). Il prend en compte les entrées successives de fonds et les éliminations opérées dans les archives non définitives. Enfin, il sert souvent de base à l'élaboration des plans de sauvegarde des fonds.

Aux Archives nationales, le récolement n'a pas de caractère obligatoire. Néanmoins, dans la perspective de la construction du site de Pierrefitte-sur-Seine (ouvert en 2013), un vaste chantier de récolement a été lancé dès 2005 au sein des fonds conservés dans le site historique de Paris, permettant de traiter près d'une centaine de kilomètres linéaires de fonds. Un premier récolement avait été mené en 1997. Le récolement lancé à partir de 2005, auquel ont été largement associées les équipes des Archives nationales, a donné lieu à la publication d'une infolettre régulière, les Échos $d u$ récolement, au ton volontairement humoristique, relatant les trouvailles réalisées au cours de ce vaste chantier.

Enfin, dans la pratique des archivistes, des récolements sont régulièrement effectués, hors du cadre réglementaire, pour faire l'état des lieux d'un fonds, en préalable par exemple au traitement d'un arriéré, afin de déterminer des documents à éliminer à l'expiration de leur durée d'utilité administrative, et de ceux à conserver au titre d'archives définitives. Qu'il soit à caractère réglementaire ou non, le récolement constitue un outil technique précieux de gestion, dont la réalisation s'avère d'une grande utilité pour permettre une bonne connaissance des fonds d'archives par les équipes qui en ont la charge. 